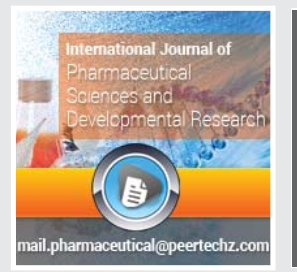

\title{
Regarding the measurement of therapeutic adherence
}

\section{Sara Malo*}

Department of Preventive Medicine and Public Health, University of Zaragoza, Spain
Received: 12 February, 2020

Accepted: 16 April, 2020

Published: 17 April, 2020

*Corresponding author: Sara Malo, Department of Preventive Medicine and Public Health, University of Zaragoza, Spain, E-mail: smalo@unizar.es

https://www.peertechz.com

Check for updates
Adherence to chronic therapies among population living in developed countries has been estimated about $50 \%$ [1]. This is a matter of concern, since poor adherence is associated with suboptimal clinical outcomes, increased frequency of adverse effects and high healthcare expenses [2].

The identification of non-adherent patients with the objective of strengthening attitudes that improve medication adherence is a complex process. First, due to the lack of a gold standard methodology that allows describing and measuring adherence. This brings up the need of getting ahead towards a consensual homogenisation [3]. Second, because adherence is a multifactorial phenomenon which depends not only on the patient but also on the disease, therapy, prescriber, social context and healthcare services characteristics [1].

Poor adherence can be the result of unintentional behaviours, such as oversights or confusion [4], frequently observed in polymedicated and elderly patients who are usually prescribed complex regimens. Furthermore, these problems can be amplified due to a declined mental function. On other occasions, poor adherence appears as a result of a deliberate decision on the part of the patient [4], due to fear to adverse effects, perception of lack of improvement or resolution, or the belief that medication is unneeded or excessive.

Based on the exposed above, there is the need of reflecting on certain issues concerning lack of adherence in polymedicated patients. Was there a negotiation and previous agreement between the prescriber and the patient when the therapeutic regimen was decided? Is the patient aware of the consequences derived from a poor disease control or from poor adherence to the prescribed medication? Was the lexical adapted to the patient reality? On the other hand, it should be wondered the priority of assessing adherence to medication in certain patients and situations. Studies aimed at analysing adherence in polymedicated patients are scarce [5]. However, before carrying out these analyses, one should ponder on some issues. Would it not be more realistic to assess the need for the coprescription of multiple drugs, rather than adherence to them? Could the simultaneous consumption of a large number of drugs itself be the cause of a loss of effectiveness and, therefore, of negative health outcomes? In this context, interventions aimed at quaternary prevention should be adopted as priority in our context.

Far from underestimating the importance of assessing medication adherence and its impact on therapy effectiveness and patient's quality of life, the objective of this text is to call for reflection on when, how and for what to measure this multicausal phenomenon in the context of a patient-centred care.

\section{References}

1. World Health Organization (2003) Adherence to Long-Term Therapies. Evidence for Action. Link: https://bit.ly/3aeSQ33

2. luga AO, Mcguire MJ (2014) Adherence and health care costs. Risk Manag Healthc Policy 7: 35-44. Link: https://bit.ly/2RHPhMf

3. Malo S, Aguilar-Palacio I, Feja C, Lallana MJ, Rabanaque MJ, et al. (2017) Different approaches to the assessment of adherence and persistence with cardiovascular-disease preventive medications. Curr Med Res Opin 33: 13291336. Link: https://bit.ly/2KbsCnz

4. Schuz B, Marx C, Wurm S, Warner LM, Ziegelmann JP, et al. (2011) Medication beliefs predict medication adherence in older adults with multiple illnesses. J Psychosom Res 70: 179-187. Link: https://bit.ly/2RHbEBL

5. Pereira F, von Gunten A, Rosselet Amoussou J, De Giorgi Salamun I, Martins MM, et al. (2019) Polypharmacy Among Home-Dwelling Older Adults: The Urgent Need for an Evidence-Based Medication Management Model. Patient Prefer Adherence 13: 2137-2143. Link: https://bit.ly/2RHFciv

Copyright: @ 2020 Malo S. This is an open-access article distributed under the terms of the Creative Commons Attribution License, which permits unrestricted use, distribution, and reproduction in any medium, provided the original author and source are credited. 